\title{
Risk analysis of impacting people and/or equipment due to rockfall
}

\author{
E Bermedo Anglo American T\&S, Chile \\ M Schellman Anglo American T\&S, Chile \\ D Diaz Anglo American Copper, Chile
}

\begin{abstract}
A risk analysis methodology due to rockfall is presented, in contrast to the conventional analysis that only considers the probability that a rock falling from certain place may pass over a containment barrier. The risk analysis methodology will also consider variables that are inherent in the site and specific conditions of the same such as for example the probability that rockfall may take place, exposure time, etc. The final value obtained will be a probability associated with one or more fatalities, which will be compared with a criterion defined to assess the risk of the sector.
\end{abstract}

Keywords: rockfall, risk analysis, fatalities

\section{Introduction}

In general terms, in order to define solutions that shall allow minimising risks associated with rockfall, work is performed with two-dimensional analysis from which rockfall probabilities in a required location is obtained. These results are compared with defined acceptability criteria and control measures adopted may be modified in accordance with the probabilities obtained, such as to incorporate and/or increase the containment barrier among others. The main deficiency of this methodology is that it corresponds to a conservative analysis since, as an example, it assumes that the probability of rockfall is $100 \%$ or in other words, that it would always be occurring. Furthermore, exposure time that any given equipment or individual could be subjected to is not considered in any part of the analysis. The objective of the analysis shown in this document is to incorporate the probabilities associated to some additional factors in order to observe the actual impact and value added when considering different solutions that many times could be of high constructive complexity and/or high cost. The main advantage of this methodology is that it allows incorporating parameters and antecedents that are valid for the specific site analysis. For example, if there is snowmelt during certain hours of the day, it is more likely that the probability of rockfall takes place during this period of time.

\section{Methodology}

First, the concepts that will be applied in this methodology will be defined:

\subsection{Probability of rockfall}

The first thing that we must do is to consider the probability of rockfall from the slope due to the change of temperature, wind, vibrations or operation (Figure 1). This concept must be particular for each operation and/or sector of analysis since it will depend on existing characteristics in each sector. For example, block and rock conditions at the slope: if there are many loose rocks, the probability that they may fall is higher than if the slope is clean. 


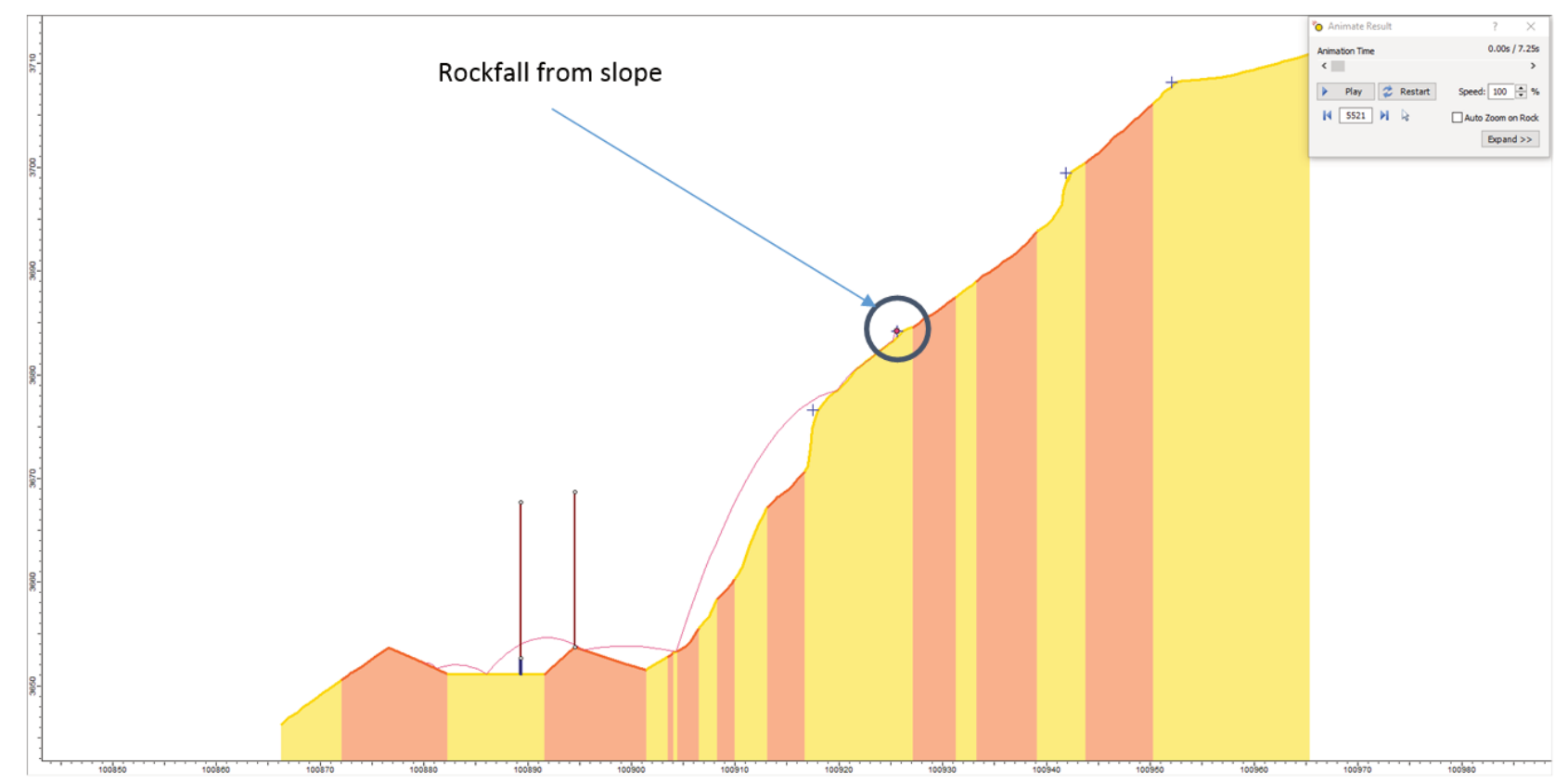

Figure 1 Schematic profile considers the concept of rockfall probability

\subsection{Probability of rockfall to sector of analysis}

This is the probability that a rockfall from slope passes over the containment barrier and falls on the ramp, platform and sector of analysis (Figure 2). This probability is obtained through a rockfall analysis software. The Rocfall software (Rocscience Inc. 2019) has been applied for the example that will be indicated.

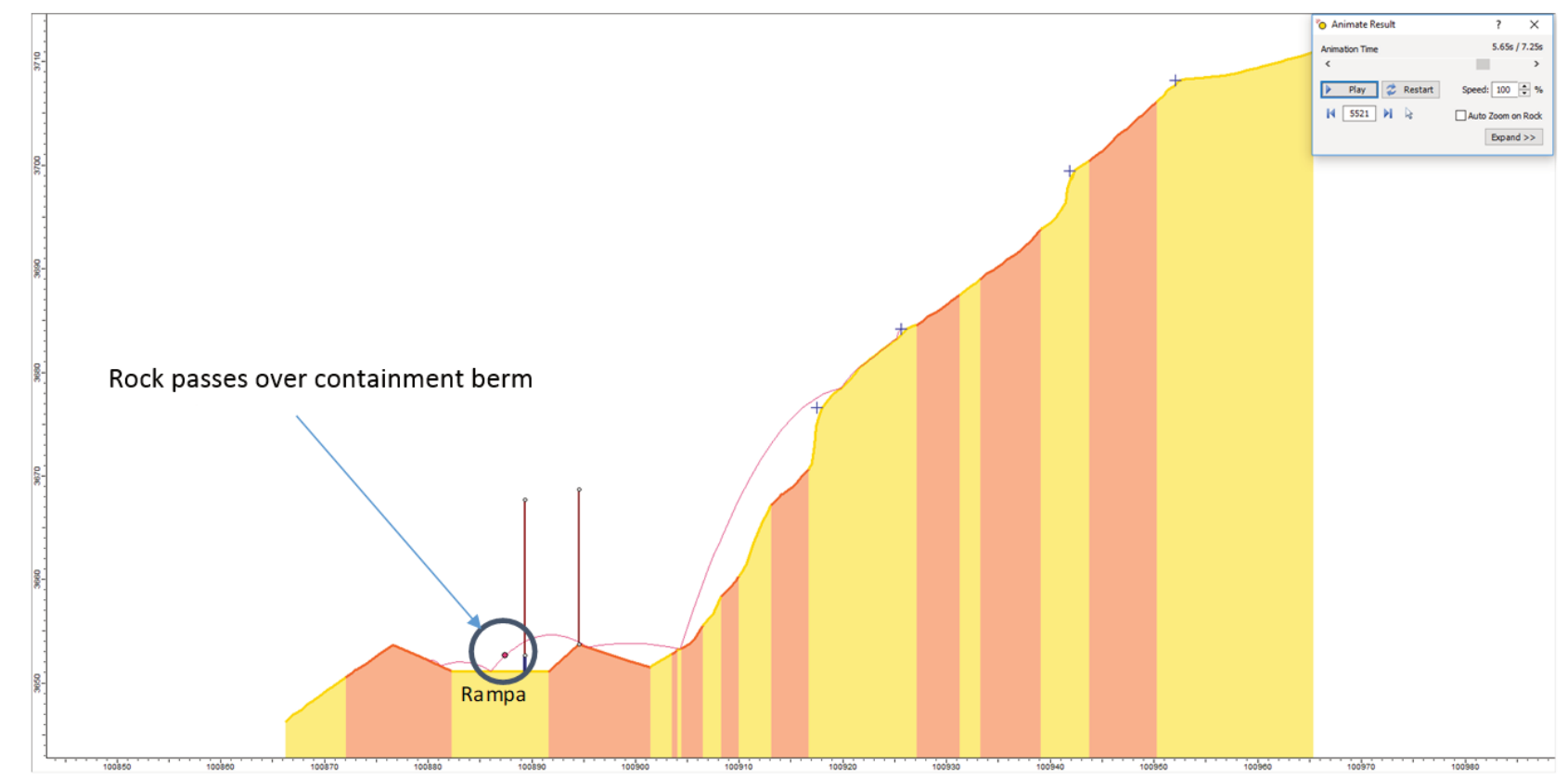

Figure 2 Schematic profile considers the concept of rock passing over containment barrier

\subsection{Probability of impacting equipment}

This is the probability that a rock that passes over the containment barrier impacts equipment that is passing by the sector (Figure 3). This is directly related to exposure time of equipment while circulating through the critical sector. 


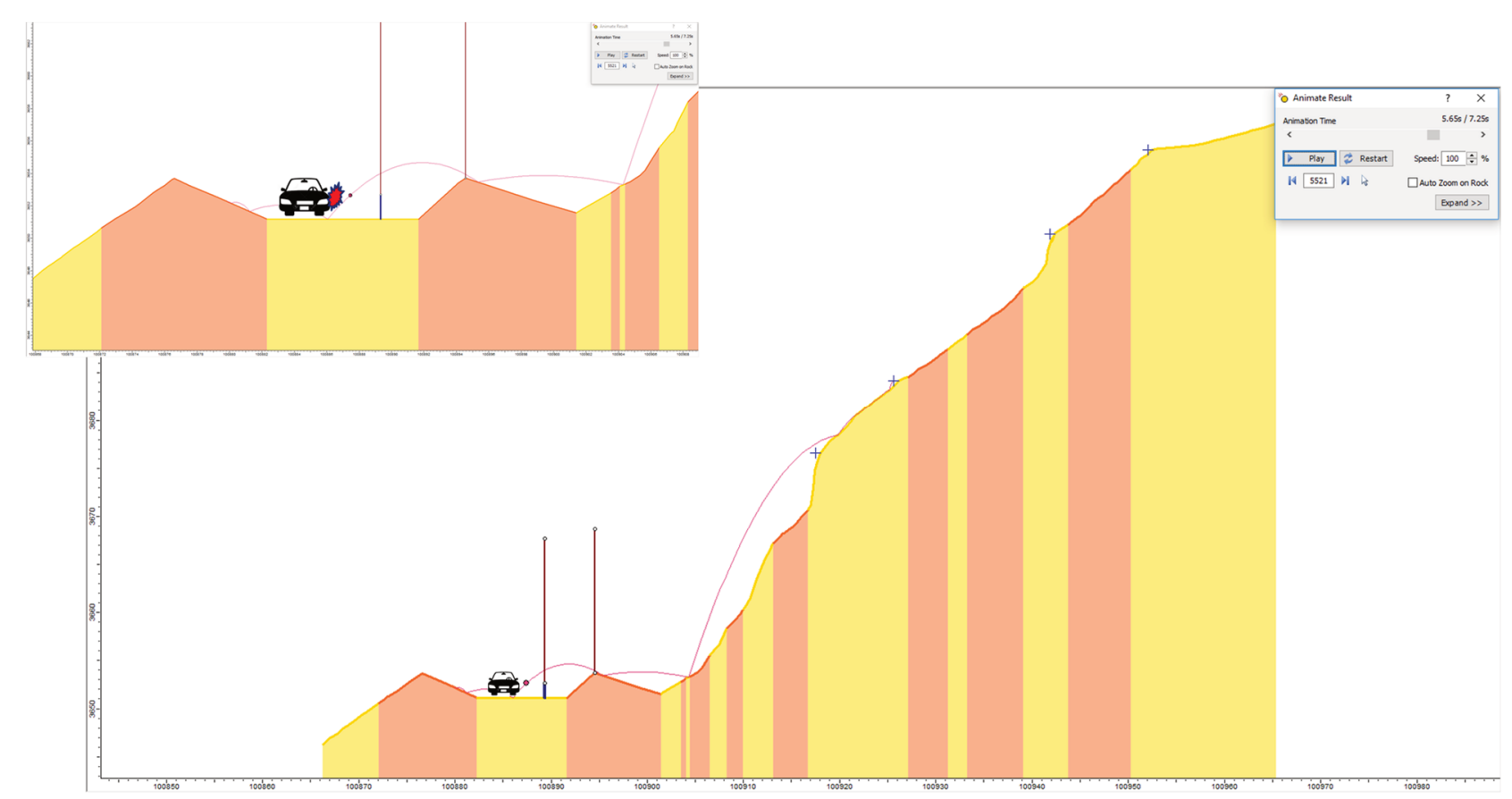

Figure 3 Schematic profile considers the concept of impacting equipment

\subsection{Probability of fatality}

This is the probability that a rock that impacts equipment causes one or more fatalities (Figure 4). This may be obtained considering the history of a certain place and/or conservatively considering a value that represents the consequence that any impact could cause a fatal injury.

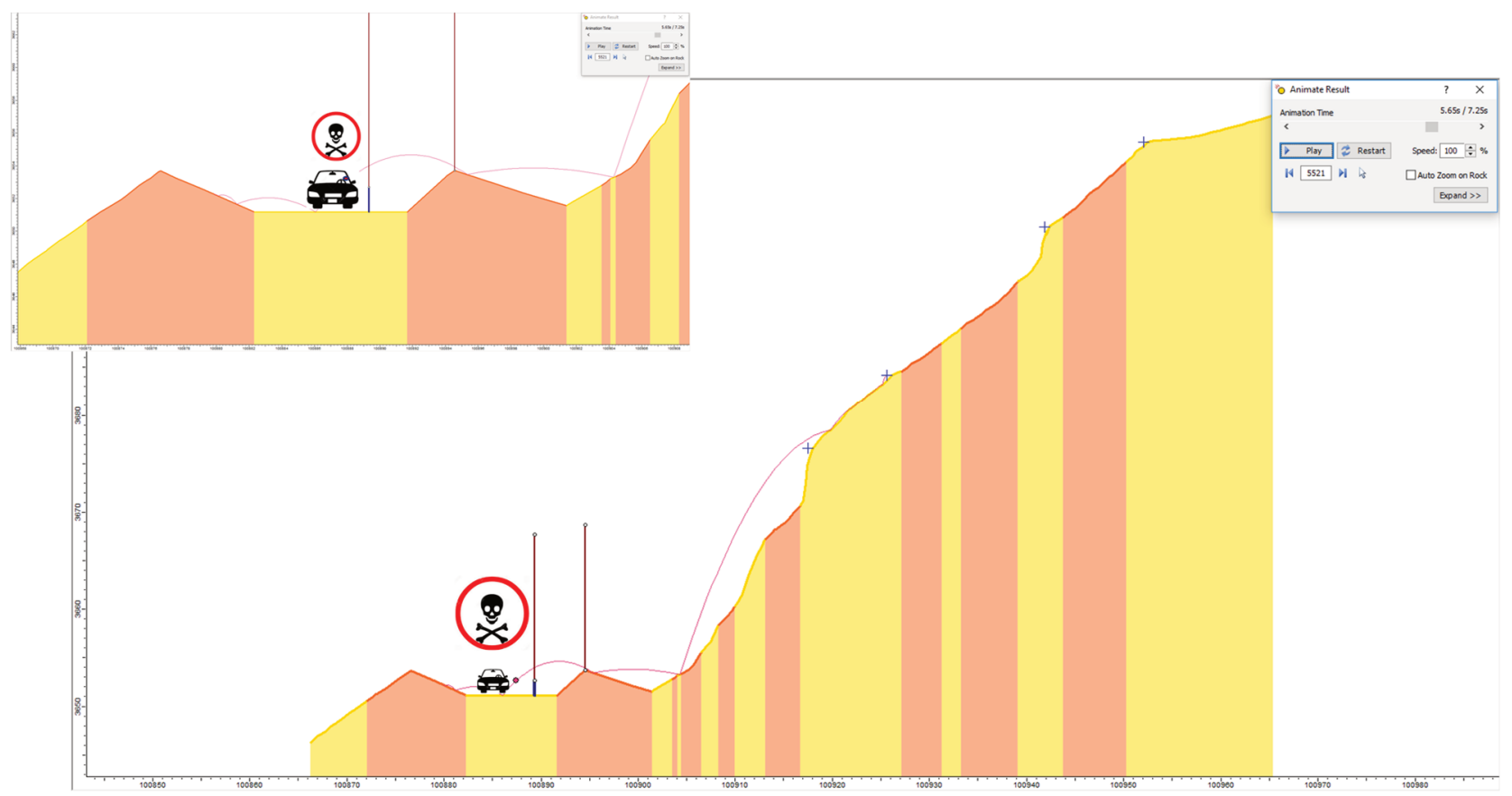

Figure 4 Schematic profile considers the concept of fatality 


\section{Calculation of fatality probability}

The result of each one of the individual probabilities, such as that shown in Equation 1, has been considered to determine the total probability associated with one or more fatalities.

$$
\mathrm{P}_{\text {Total Fatality }}=\mathrm{P}_{\text {Rockfall }} \times \mathrm{P}_{\text {Rockfall to Ramp }} \times \mathrm{P}_{\text {Impact on Equipment }} \times \mathrm{P}_{\text {Fatality }}
$$

where:

$\mathrm{P}_{\text {Total Fatality }}=$ Probability that a rock falling from slope passes over the containment barrier impacts equipment that is circulating and as a result causes one or more fatalities.

\section{$4 \quad$ Acceptable fatality probability}

Acceptable fatality probability will be defined as the probability that a healthy individual between 11 and 20 years of age dies due to natural causes. This value, as indicated by the World Health Organization (2019), is about $0.65 \%\left(0.0065\right.$ or $\left.6.5 \times 10^{-3}\right)$.

\section{$5 \quad$ Example of application}

The aforementioned methodology will be applied as an example in a representative profile of the blue water ramp sector at Los Bronces Operation. Restitution coefficients are calibrated through back-analysis.

\subsection{Rockfall probability}

A detailed control of rockfall was performed during 16-19 September 2017 at the blue water ramp sector, where the quantity of rockfall and the hours of such rockfall during the aforementioned period was registered. This is summarised in Table 1.

Table 1 Summary of rockfall events during 16-21 September 2017 period (quantity)

\begin{tabular}{lllllll}
\hline Hours & 16 Sept. & 17 Sept. & 18 Sept. & 19 Sept. & 20 Sept. & 21 Sept. \\
\hline 07:30-10:00 & 0 & 20 & 1 & 5 & 5 & 6 \\
10:00-18:00 & 14 & 4 & 54 & 53 & 29 & 37 \\
18:00-07:30 & 0 & 2 & 1 & 2 & 0 & 0 \\
\hline
\end{tabular}

With the aforementioned information, it has been conservatively considered that each event associated with rockfall lasted $5 \mathrm{~min}$, in order to be able to establish the percentage of time that rockfall has occurred. This time is shown in Table 2.

Table 2 Summary of time associated with rockfall events during 16-21 September 2017 period $(\min )$

\begin{tabular}{lllllll}
\hline Hours & 16 Sept. & 17 Sept. & 18 Sept. & 19 Sept. & 20 Sept. & 21 Sept. \\
\hline 07:30-10:00 & 0 & 100 & 5 & 25 & 25 & 30 \\
10:00-18:00 & 70 & 20 & 270 & 265 & 145 & 185 \\
18:00-07:30 & 0 & 10 & 5 & 10 & 0 & 0 \\
\hline
\end{tabular}


Finally, time percentage and total average when rockfall has taken place has been obtained for each period of observation and is shown in Table 3.

Table 3 Summary of time percentage with rockfall events during 16-21 September 2017 period (\%)

\begin{tabular}{llllllll}
\hline Hours & 16 Sept. & 17 Sept. & 18 Sept. & 19 Sept. & 20 Sept. & 21 Sept. & Average \\
\hline 07:30-10:00 & $0 \%$ & $67 \%$ & $3 \%$ & $17 \%$ & $17 \%$ & $20 \%$ & $21 \%$ \\
10:00-18:00 & $15 \%$ & $4 \%$ & $56 \%$ & $55 \%$ & $30 \%$ & $39 \%$ & $33 \%$ \\
18:00-07:30 & $0 \%$ & $1 \%$ & $1 \%$ & $1 \%$ & $0 \%$ & $0 \%$ & $1 \%$ \\
\hline
\end{tabular}

With the aforementioned information, if we consider average values, such events have been grouped into two hourly periods. One group is between 10:00 and 18:00 and the second group is between 18:00 and 10:00. This is aligned with that which was observed in field, since it is more frequent to have slope rockfall when the temperature begins to increase between 10:00 and 18:00. Even then, a value close to twice the probability of harming or damaging has been applied conservatively.

Given the aforementioned and considering the particular condition of the blue water ramp, it has been considered that the main variable that affects this probability is associated to high temperatures and snowmelt, thus, the following probabilities segregated by hours have been defined:

- There will be a $60 \%$ probability between $10: 01$ and $18: 00$.

- There will be a $40 \%$ probability between $18: 01$ and 10:00.

As indicated previously, the probabilities applied are conservative assumptions that take into account the experience available regarding the behaviour of this sector, where it is required to differentiate that during certain hours of the day it is much more likely that rockfall takes place.

In addition to that which is indicated in previous paragraphs, this condition could vary seasonally since during summer or winter, period conditions are better than those considered in this document. The worst-case scenario has been considered for the analysis performed, which is when snowmelt is registered.

\subsection{Rockfall to ramp probability}

This probability is obtained through the two-dimensional analysis while considering the original topography and proposed containment measures. In this case, the Rocfall software (Rocscience Inc. 2019) has been applied, where the probability of rockfall on the ramp is $10.17 \%$ (Figure 5 ).

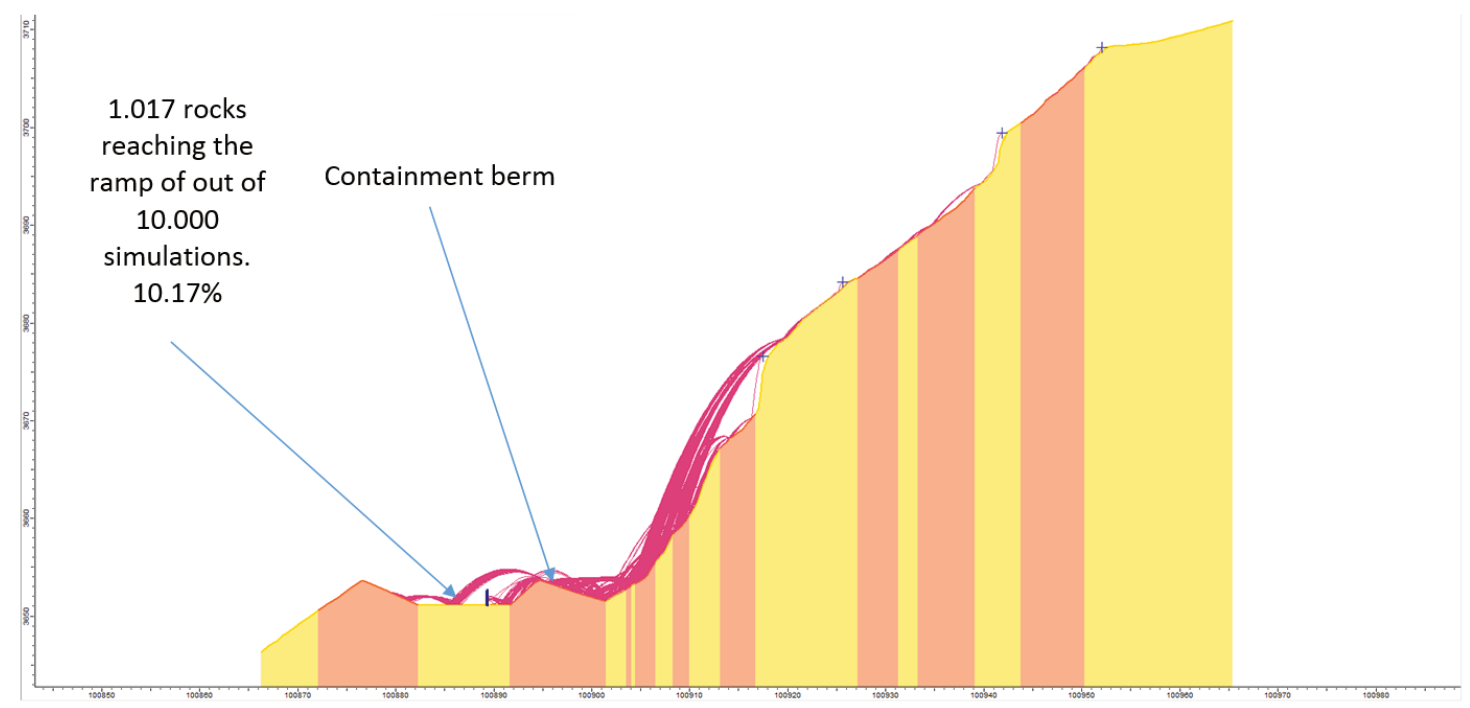

Figure 5 Rockfall analysis example $-10.17 \%$ of rocks reaching the ramp 


\subsection{Probability to impact vehicle}

This variable is directly related to the exposure time of equipment while it circulates through the critical sector. The following assumptions have been considered for our analysis:

- $500 \mathrm{~m}$ to cover.

- Average speed $40 \mathrm{~km} / \mathrm{hr}$.

- Lateral area of influence $40 \mathrm{~m}$.

With the aforementioned assumptions, it is possible to indicate that total exposure time under the condition of potential rockfall will be the distance to cover divided by the average speed, which is a total of $45 \mathrm{~s}$ to circulate through the whole sector. This does not imply that a vehicle will be exposed for $45 \mathrm{~s}$, since the actual exposure time will be the percentage of such time that the vehicle may be affected.

The lateral area of impact has been defined for the aforementioned in the event of rockfall. Considering the geometry of the blue water area, it has been determined that the lateral impact of a rockfall event will be $40 \mathrm{~m}$. In other words, following the same methodology indicated in the previous paragraph, actual exposure time in the event of rockfall is of $3.6 \mathrm{~s}$.

Considering exposure time in the event of rockfall ( $3.6 \mathrm{~s})$ and total circulating time ( $45 \mathrm{~s}$ ), one can determine time percentage when a vehicle may be impacted, which is obtained when dividing exposure time by total travel time, which gives an $8 \%$ probability.

With the aforementioned, it can be indicated that the percentage of total time to cover $(500 \mathrm{~m})$ while exposed for equipment in a $40 \mathrm{~m}$ direct impact area is $8 \%$.

\subsection{Probability to cause one or more fatalities}

Despite the fact that there are no antecedents available at Los Bronces regarding an event of rockfall that has caused fatalities, it has been considered that the probability of a fatality as a result of an impact of a rock on equipment is $70 \%$. This value could vary for other exercises but for our case, we have arbitrarily adopted the value of $70 \%$. This assumption is extremely conservative since there is no registry at Los Bronces Operation that a fatality has been caused by a rockfall event.

\subsection{Fatality probability for this example}

As indicated in Equation 1 and while replacing the values obtained for the case of this example, the probability of fatality would be the following:

- Valid for the following hours, between 10:01 and 18:00.
$\circ \quad P_{\text {Total Fatality }}=0.6 \times 0.1017 \times 0.08 \times 0.7$.
$\circ \mathrm{P}_{\text {Total Fatality }}=0.342 \%\left(3.42 \times 10^{-3}\right)$.

- Valid for the following hours, between 18:01 and 10:00.

$\circ P_{\text {Total Fatality }}=0.4 \times 0.1017 \times 0.08 \times 0.7$.

$\circ \mathrm{P}_{\text {Total Fatality }}=0.228 \%\left(2.28 \times 10^{-3}\right)$.

\section{Conclusion}

The methodology applied allows incorporating variables that two-dimensional analysis do not take into account. The values obtained allow improving the estimate and quantify in a better form the risk for people and equipment that circulate through the sector, taking into account specific conditions of the site of analysis. 
If we had developed this analysis in accordance with current methodology; that is, only considering the probability that a rock falling from the slope passes over the containment barrier; we should have proposed a solution where such barrier should be capable of containing at least $95 \%$ of the rocks.

In the case presenting the barrier, it only contains approximately $90 \%$ of rocks and despite such, we have demonstrated that the system is safe enough to operate without risks that are greater than the original case.

According to the analysis obtained from the example, the total fatality probability is $0.342 \%$, which is less than the acceptable fatality probability criterion of $0.65 \%$, which means that the risk of circulating through this sector is significantly below the risk that a healthy individual between 11 and 20 years of age has to die due to natural causes.

\section{References}

Rocscience Inc. 2019, RocFall, version 6.0, computer software, www.rocscience.com

World Health Organization 2019, Global Health Observatory data repository, https://apps.who.int/gho/data/node.main.687?lang=en 
